\title{
PHOTOGRAPHIC STUDIES ON SNOWFALL INTENSITY IN CONNECTION WITH VISIBILITY IN A SNOWFALL
}

\section{Abstract}

\author{
by
}

H. Konishi, T. ENDOH, Y. Fujtyoshi and G. WAKaHama

Institute of Low Temperature Science, Hokkaido University, Sapporo, Japan 060

It is important to have exact values of snowfall intensity (mass flux) in the evaluation of the amount of snowfall (ie water equivalent of snow) by means of a snow gauge or from intensity of radar echo. Since continuous measurements entail unlimited labor and time, some convenient optical method that records automatically, such as a visibility meter, is desirable.

Visibility $\mathrm{V}$, during a snowfall, water equivalent of snow $W$, and snowfall intensity $R$, are closely connected to each other, because are dependent on the number concentration $N$, size $D$, fall velocity $v$ and apparent density $\rho$ of snow particles or snowflakes falling near the ground. Though it has been hoped to reveal relationships between them, these have remained unknown. This may be due to the lack of appropriate methods of simultaneous measurement for obtaining $N, D, v, \rho$ and even $R$ for a considerable duration continuously. In order to clarify the relationship between $R$ and $N, D, v$ and $\rho$, photographic observations were conducted continuously to measure these quantities simultaneously.

Visibility V ( $\mathrm{km})$, was continuously observed during a snowfall by the use of the laser visibility meter, while snowfall intensity $\mathrm{Ro}_{0}(\mathrm{~mm} / \mathrm{hr})$ was observed to measure the weight of snow collected in a vat for several minutes. The relationship between them is shown as:

$$
\mathrm{Ro}=\mathrm{AxV}^{-3 / 2}
$$

where $\mathrm{A}$ is taken as 1.0 conventionally.

A tower $3 \mathrm{~m}$ high, 0.9 by $0.6 \mathrm{~m}$ in horizontal cross sectional area, was installed on the roof of the ILTS main building, and the trajectories of snow particles or snowflakes just falling in the tower was taken under a stroboscopic light every minute by the use of a $35 \mathrm{~mm}$ camera with a telephoto-lens, fixed 6 meters away from the tower.

The photographs thus obtained yield $N, D$ and $v$ for individual snow particles, but not information for $\rho$. Then assuming the empirical relation between $v(\mathrm{~cm} / \mathrm{s})$ and $\rho$ $\left(\mathrm{g} / \mathrm{cm}^{3}\right)$ obtained for snowflakes, ie

$$
v=330 \times\left(p-p^{\prime}\right),
$$

where $\rho^{\prime}$ is the density of air $\left(\mathrm{g} / \mathrm{cm}^{3}\right)$, $\rho$ can be obtained as a function of $v$.

If we assume that the snow particle is spherical, then $\mathrm{R}$ and $\mathrm{V}$ can be expressed as

$$
r=\frac{\pi}{6} \Gamma\left(N \times D^{3} \times \quad p \times v\right)
$$

and

$$
V=\frac{\pi}{4}\left[\left(N \times D^{2} \times K\right),\right.
$$

respectively, where $\mathrm{D}$ is the diameter of a snow particle and $\mathrm{K}$ is the transmittance. Furthermore, the coefficient $\mathrm{A}$ in the equation (1) is expressed as $\mathbf{A}=\mathrm{C} \mathbf{x} p \mathbf{v} \mathbf{N}^{-\frac{1}{2}} \mathbf{x}$ $\mathrm{K}^{-3 / 2}$ from equations (3) and (4), among them

$$
\text { o } \mathrm{x} \mathrm{K}^{-3 / 2}=\text { constant }
$$

in the case of our observation.

The values of $R$ obtained from the four methods, as tabulated in Table 1, are compared with Ro. On the basis of the results obtained in these studies, the relationships of dependences will be discussed in connection with visibility and snowfall intensity. It was found that fall velocity $v$, or transmittance $K$, have to be measured to obtain snowfall intensity as well as visibility.

TABLE 1

\begin{tabular}{llll}
\hline & original & procedure \\
\hline (a) & V & $(1)$ & $\mathrm{R}(\mathrm{a})$ \\
(b) & V, Photo (N, D) & $(4),(5),(3)$ & $\mathrm{R}(\mathrm{b})$ \\
(c) & Photo (N, D, v) & $(2),(3)$ & $\mathrm{R}(\mathrm{c})$ \\
(d) & Photo (N, D, v) & $(2),(5),(4)$, (1) R(d) \\
\hline
\end{tabular}

